\title{
More fiddling with the definition of death?
}

\author{
John M Stanley Lawrence University, USA
}

In the last paragraph of his otherwise excellent article 'Why Let People Die?' Fournal of Medical Ethics, June, 1986, Grant Gillett, New Zealand-trained neurosurgeon and Oxford philosopher, raises several important questions that he fails to resolve and that require further illumination.

Gillett claims that he is not 'fiddling about' with the definition of death, but it seems clear both from the tone and the direction of his argument that that is precisely what he is intending. Indeed, the very sentence that begins with the disclaimer that he is not, ends with what seems, from an ethical perspective, to be intended as a working definition of death: '. . . this person is no longer, in any ethically interesting sense, alive'.

Gillett distinguishes between the body of his former patient and the person who previously was his patient. The person is no longer 'here'. 'Jim is not with us anymore'. Jim's body may be in some biological sense alive, but what we really care about protecting, both in our laws and in our ethical arguments going back to Locke, is the person. The body of such a 'former person' may, however, be not only inconveniently but stubbornly alive - at least in any reasonable biological definition of that term. That body may be helpless and almost totally non-sentient. It may be, ethically speaking, indistinguishable from a cadaver, but, biologically speaking, it is not yet a cadaver; it is alive, and, unfortunately, may remain so for some time. And this is precisely what Gillett does not remind himself or his readers of at this point: the body of the former patient is technically alive. It seems to me that this is where Gillett fails us. He must either maintain the distinction between a live body that is no longer capable of any person-qualifying functions and a cadaver that is biologically dead or he must admit that he is 'fiddling about with the definition of death' and work out the consequences of his proposed definition.

Indeed, Gillett's next sentence: 'The reason that I demur from saying that we should extend the definition of death to a state of irreversible coma or to

\section{Key words}

Brain death; persistent vegetative state; concept of the person. the persistent vegetative state is that I have not pursued the possibilities of a "Sorites argument" once this move $\omega$ is made' makes it clear that he is seriously $\vec{\sim}$ considering the explicit extension of the definition of $\vec{a}$ death to include decortication. Gillett's position is, 을 thus, closer to that of those who want to argue for neocortical death as the relevant death criterion (for example, $\mathrm{H} \mathrm{K}$ Beecher (1)) than it is to those who want $\overline{\widehat{c}}$ to hold to brain stem death as the only justifiable death criterion (for example, B Jennett $(2,3)$ and C Pallis, $\stackrel{\infty}{\mathscr{\infty}}$ (4)).

In his final extraordinary sentence Gillett raises a host of troublesome problems he has not prepared us for. He seems to be saying that this body which is, 'in $\frac{\bar{\partial}}{\mathrm{O}}$ every ethical sense, no longer alive,' is really to be ٌ considered dead at least in the sense that whatever the $\stackrel{\mathbb{Q}}{\propto}$ next of kin wanted to do with it he or she could. What $\overrightarrow{\vec{B}}$ are these 'other decisions about his body' that can now $\frac{9}{3}$ be made by the next of kin? Are there really to be no more limits on our behavior with respect to it than the limits that now obtain for the treatment of cadavers? What if the next of kin wanted to use the kidneys or heart of this body that 'is no longer in any ethically $:$ interesting sense alive' for another member of the 3 . family who needed a life-saving transplant? Would that $\delta$ decision be justified? What if the next of kin decides that he would like to keep that body (in which the 윽 former patient no longer has any interest) 'alive' for as long as technically possible as a 'living' organ bank for possible future family emergencies? Could that $\bar{N}$ decision be justified? Could a death certificate be o issued with all of its legal implications, including inheritance of property?

In short, it seems that Gillett has failed to be rigorous in his distinctions precisely at that point where it is so 0

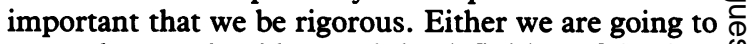
argue that we should extend the definition of death to $\stackrel{?}{+}$ include decortication or we are not. If we are, we must face squarely a host of implications that seem to run counter to current clinical practice and most current $\stackrel{D}{\overparen{D}}$ public sentiment, including the implication that all $\stackrel{\mathbb{Q}}{\varrho}$ those patients in nursing homes in a persistent vegetative state are ethically indistinguishable from cadavers.

One can agree with Gillett's sensitive and careful probing of the ethical dilemma presented to him as a 
practising clinician. One can agree with him that a decorticate body is not a person in the sense that that concept has been used traditionally. One can agree that it makes good ethical sense to say to the family ' Jim is not with us any more'. One can certainly agree that 'an intensive resuscitation and support regime' for such patients is not ethically indicated even if it could be medically 'successful'. (Some have even gone further, suggesting that prolonging the lives of patients in a persistent vegetative state may be ethically wrong because it is actually harming them - essentially condemning them to 'a fate worse than death' (4). But it is not so easy to agree that the way to solve these terribly difficult problems is to attempt to define them away. In fact, I cannot agree with that at all.

There are several compelling reasons, both theoretical and practical, for not fiddling further with the definition of death at this time. First, there is, at the present time, no simple operationally sound test for the persistent vegetative state. There are tests for brain stem death that properly trained emergency room doctors and even some paramedics can administer without complications, but the determination of irreversible decortication is far less clear cut and normally requires careful and long-term clinical examination $(2,3,4,6)$. More importantly, there is a certainty about the non-reversibility of brain stem death that does not obtain for decortication (1). No one ever 'recovers' from a dead brain stem. That is precisely why, as Jennett and Pallis have pointed out repeatedly, brain stem death is such a reliable definition of death. While recovery from a persistent vegetative state after longer than one month is rare and even rarer after a longer peiod of time, the irreversibility of the condition has not reached and is not likely to reach the level of certainty of brain stem death $(3,4,5,6,7)$. Finally, however clear it may be that their lives as persons are over, patients in a persistent vegetative state are still, biologically speaking, very much alive. As $\mathrm{C}$ Pallis has pointed out in correspondence to the British Medical fournal: 'These unfortunate individuals breathe and swallow spontaneously and may grimace or withdraw their limbs in response to painful stimuli'. They may, Pallis speculates, even have the capacity for some consciousness though that capacity will not likely be 'endowed with any (hemispherically determined) content'. That the capacity for consciousness is theoretically intact and could be endowed with fragments of lingering sentience causes Pallis to comment that a 'fate worse than death' may be a far more accurate description of patients in this unfortunate state than 'those who sketched this vivid image may have imagined' (8).

Patients in a persistent vegetative state may not be persons, in an ethical sense, but that fact does not put an end to our responsibility to the biological remains. The management of their care presents us with terribly difficult ethical challenges, but resolving these challenges by extending the definition of death to include the persistent vegetative state is just not on whatever we may discover from an exhaustive examination of the Sorites paradox. Indeed it would seem that we are stuck, for the time being at least, with an intermediate moral category: a decorticate body which must be understood unequivocally as not yet dead, although still not a live person 'in any ethically interesting sense'. The questions of what can be done to these live human bodies who are no longer persons, of who makes the decisions regarding their treatment, of what procedures medical practice should insist on for the decision-making process, and of what role, if any, the law should play in these issues are all extremely important questions to which society and the medical profession are going to have to address their very best thinking, but they cannot be adequately addressed by defining this perplexing intermediate category out of existence.

It is indeed instructive to find a neurosurgeon who is also a philosopher addressing these questions and I commend $\mathrm{Mr}$ Gillett for raising them and for the helpful and sensitive reasoning up to the last page of his article, but the very difficult questions he raises on that last page, indeed in the last paragraph of that article, demand more careful examination by both the philosopher and the brain surgeon if such address is to be illuminating.

Fohn M Stanley PhD is Edward F Mielke Professor of Ethics in Medicine, Science and Society, Lawrence University, USA.

\section{References}

(1) Beecher H K. The new definition of death, some opposing views. Unpublished paper summarised in Veatch R. Death, dying, and the biological revolution. New Haven: Yale University Press, 1976: 38-42.

(2) Jennett B. Diagnosis of brain death. Fournal of medical ethics 1977 ; 4-5.

(3) Jennett B, Plum F. Pesistent vegetative state after brain damage. Lancet 1972; I: 734.

(4) Pallis C. An A B C of brain stem death. London: British medical journal, 1983.

(5) Pallis C. Whole-brain death reconsidered. Fournal of medical ethics 1983; 9: 32-37.

(6) Campbell A G M. Children in a persistent vegetative state. British medical journal 1984; 289: 1022-1023.

(7) Feinberg W M, Ferry P C. A fate worse than death: the persistent vegetative state in childhood. American journal of the disabled child 1984; 138: 128-30.

(8) Pallis C. Correspondence. British medical journal 1984; 289: 1307. 